\title{
"Day Hospital in Child and Adolescent Psychiatry: Is It Effective for Whom?" Effectiveness of Infant Psychiatric Day Hospital
}

\author{
Renata Mendonca $^{1 *}$, Telma Pantano ${ }^{2}$, Caio Borba Casella ${ }^{2}$ and Sandra Scivoletto ${ }^{2}$ \\ ${ }^{1}$ Faculdade de Medicina FMUSP, Universidade de Sao Paulo, Sao Paulo, Brazil \\ ${ }^{2}$ Department of Psychiatry, Faculdade de Medicina FMUSP, Universidade de Sao Paulo, Sao Paulo, Brazil
}

*Corresponding Author: Renata Mendonca, Faculdade de Medicina FMUSP, Universidade de Sao Paulo, Sao Paulo, Brazil, Tel: +55 11 974533994; Fax: 29795591; E-mail: resilvamendonca@ gmail.com

Received: 12 October 2017; Accepted: 06 November 2017; Published: 10 November 2017

\begin{abstract}
The infant day hospital is a therapeutic option to patients with high complexity neuropsychiatric disorders. It is essential to evaluate its effectiveness and the patients' profile that better respond to this type of intervention so the national resources are better invested.

Objectives: (1) to describe the population admitted in a psychiatric infant day hospital (HDI); (2) to evaluate the clinical response to this intervention and (3) to identify predictive factors of dropout.

Methods: All patients ( $n=62)$ admitted to our HDI unit were evaluated and received multidisciplinary treatment for a 3-month period from 2011 to 2014. The psychiatric diagnostic interviews, patients' records analysis and the clinical scales Children's Global Assessment Scale (CGAS) and Clinical Global Impressions Scale (CGI) were the measures used for outcome evaluation.

Results: The mean age was 13 years old (SD: 3.1 years). Thirty-five patients (56.5\%) were male and 53 patients (83.9\%) referred occurrence of family conflicts. The most prevalent initial diagnostic was Mood Disorder ( $\mathrm{n}=28$, 45.1\%). The mean C-GAS increased from 36 to $52(\mathrm{p}=0,00)$ and the mean CGI decreased from 5 to 2 ( $\mathrm{p}=0.00$ ) during the period. Older patients presented higher odds to abandon the treatment in HDI $(O R=0.448 ; p=0.019)$ as well as those with a relative with affective disorder ( $O R=2.303 ; \mathrm{p}=0.003)$.

Conclusion: The HDI was effective in promoting clinical stabilization of severe psychiatric disorders in children and adolescents. It is important to address factors such as the age of the patients and the psychopathology in the family to try to decrease dropout rates.
\end{abstract}


Keywords: Psychiatric disorders; Day treatment; Children; Treatment outcomes; Mental health

\section{Introduction}

It is estimated that the prevalence of psychiatric disorders among children and adolescents worldwide and in Brazil is about $15 \%$ [1-4]. The occurrence of mental illness in this population can culminate in cognitive and emotional impairment, disturb the child's global functioning, alter the learning and professional formation on adulthood, causing relationship problems and poorer quality of life. Mental disorders during childhood and adolescence also increase the risk of criminality and substance abuse later on $[2,5,6]$. Therefore, identification and development of early interventions are paramount to minimize the future impairments.

The Brazilian Mental Health Policy for Children and Adolescents combined with the Mental Health National Policy intend to avoid individual institutionalization and exclusion from the community [7]. The challenge is to articulate a "care system" with different levels of complexity and a multidisciplinary network - including education, social assistance and justice - to meet specific demands: resilience promotion, universal and selective prevention, early interventions, and rehabilitation programs. Specifically regarding treatment, the health system is composed by primary attention, psychosocial attention centers (CAPS), hospital services (emergency care, day hospital, hospitalization) and community centers [8]. The type and intensity of a therapeutic intervention vary according to specific demands of each individual in a certain moment. In all of them, a multidisciplinary approach is essential, aiming not only to obtain clinical stabilization, but also to develop abilities and enhance personal capacities, to develop interventions of prevention and health promotion, and to promote and increase resilience [9].

The integration of the multiple services that compose the health care network is fundamental to ensure easy access to treatment, its maintenance and to promote changes in the level of complexity of treatment interventions to adapt to individual needs throughout time, preventing the worsening of the disorders [7]. Nonetheless, according to the Brazilian Psychiatry Association [10] half of the infants with psychiatric disorders don't receive adequate treatment in Brazil [10]. This disparity between demand and medical assistance can be partly explained by the lack of specialized professionals (only $2.02 \%$ of the total Brazilians psychiatrics have certification in child and adolescent psychiatry). However, it is mainly due to the lack of specialized services: in 2014 there were only 201 CAPS for children and adolescents in all country [11]. The lack of adequate treatment leads to a greater severity of cases, increasing the demand for higher complexity services - the hospital services. Nonetheless, to follow the guideline of Mental Health National Policy for Children and Adolescents, and primarily, to avoid hospitalization, it is necessary to seek effective alternatives to integral psychiatric hospitalization. Therefore, it is crucial to assess the demands of each patient and evaluate the effectiveness of the services, so that the patients can be directed to services that better meet their necessities, resulting in a more effective care and optimizing the use of existing resources.

The day hospital is a therapeutic option to patients with high complexity neuropsychiatric disorders, that require intensive care and constant supervision, but who can rely on a structured support when they are not at the health service. In contrast with the integral hospitalization, the day hospital represents no rupture with their family and community; so the stigma related to a psychiatric hospitalization is minimized [12, 13]. Moreover, the day hospital 
is a resource to shorten the length of an integral hospitalization. The day hospital, when directed to children and adolescents with neuropsychiatric disorders, could also be an important reference in the network of the Mental Health National Policy for Children and Adolescents, if its effectiveness is confirmed.

Previous researches have demonstrated that day hospital is an effective treatment, in short and long term, for children and adolescent with psychiatric disorders $[12,14,15]$. However, the pattern of response varies greatly [16, 17]. One of the factors related to treatment response is the length of patient remains on the intervention [16]. The early dropout is related with therapeutic failure [18, 19], being a frequent problem of most of psychiatric interventions, including day hospitals [20].

To enhance the effectiveness of an intervention, it is essential to know the patients' profile that better respond to it, as well as knowing the predictive factors of early dropout. However, in search conducted in the databases PubMed and Scielo there were found only two Brazilians studies about adults attended in a psychiatric day hospital [21, 22]. No studies regarding psychiatric day hospital for children and adolescents were found. To fulfill this gap, the aims of this study are: (1) to describe the population admitted in a psychiatric infant day hospital (HDI); (2) to evaluate the clinical response to this intervention and (3) to identify predictive factors of dropout. Therefore, it is expected to strengthen the children and adolescents mental health care, contributing to a better articulation of services that composes the mental health care network of the Mental Health National Policy for Children and Adolescents in Brazil.

\section{Methods}

The sample was composed by all patients that were admitted to the Psychiatric Infant Day Hospital (HDI) from the Institute of Psychiatry, Hospital das Clinicas HCFMUSP, Faculdade de Medicina, Universidade de Sao Paulo, Brazil, during 2011 to 2014. The participants were referred to the HDI from the children and adolescents psychosocial attention centers (CAPS-I), from the inpatient unit of Institute of Psychiatry or from private clinics. The Institute of Psychiatry from the Hospital das Clinicas is a quaternary health service, a reference service for the state of Sao Paulo and eventually for others Brazilians states.

The HDI from the Institute of Psychiatry started its activities on April, 1997. In 2009, the therapeutic project was reformulated aiming to integrate the HDI as an additional resource for the local mental health care network. The goal is to offer multidisciplinary treatment for children and adolescents with severe mental disorders in exacerbation or destabilization phase, that require intensive intervention, in order to establish sufficient recovery so that they can continue treatment on an outpatient basis or in rehabilitation and external monitoring programs, such as the CAPS-I.

During day hospital treatment patients have intensive daily care, but maintain family life at night. The interventions are multidisciplinary, of diagnostic purposes (psychiatric evaluation, neuropsychological evaluation, speech and learning assessment, occupational therapy, psychomotricity evaluation, social assistance) therapeutics (psychiatry, psychotherapy, family therapy/orientation and social assistance), and school support (hospital class). The maximum capacity is of eight patients, that are accompanied by a responsible adult at all time (usually, the mother of the 
patient). This adult also receives specific interventions, such as family therapy, parental training and individual psychotherapy.

The initial evaluation is performed by the multidisciplinary team on the first two weeks at the HDI. At the end of this period, the diagnostic hypothesis are established and the therapeutic plan is drawn up and started. The interventions continue during the next six to eight weeks. On the last two weeks, after the clinical stabilization, the patient is gradually referred to outpatient services to continue his/her treatment, to go back to school and to start external activities. Eventually, in cases that there is no response to the performed interventions, the patients are referred to integral hospitalization (inpatient treatment).

\subsection{Sample}

For this study, the inclusion criteria were the same adopted in the HDI admission. They were: 1) children and adolescents between 5 and 17 years and 6 months old, with the diagnostic of severe mental disorder in acute phase, demanding intensive care, by failure of outpatient treatment; 2) minimum impulse control capability, being able to stay in a day hospital; 3) minimum competence in basic activities of daily living and in instrumental activities; 4) family support that allows staying in family environment; (5) availability of a responsible and patient to attend daily activities of the HDI, from Monday to Friday; and (6) patient and his/her responsible have to agree with HDI rules and to take part in this study.

The exclusion criteria for the HDI follow-up were: 1) Those with severe disorder that require inpatient treatment; 2) Lack of family and/or social support. From the 72 patients that were referred to HDI from 2011 to 2014, 62 were included in this study, as the other $10 \mathrm{did}$ not meet the requirement criteria. During the research period, five patients required inpatient treatment. Three of them returned to the HDI to continue treatment, and were, therefore, included in the study. Two of them did not return for follow-up at the HDI, so they were excluded from the study.

\subsection{Data collection and instruments}

To obtain the socio demographic characteristics, patients' records were analyzed. Information regarding living situation, family dynamics (parental union, numbers of siblings, absence of a parent figure, family conflicts domestic violence, physical, emotional or sexual abuse), the need to trigger children/adolescents' protection services and presence of psychiatric disorders among other family members were also obtained on patients' records. The Children's Global Assessment Scale (CGAS) and Clinical Global Impressions Scale (CGI) were used to evaluate functioning and clinical severity. Both scales were applied at the beginning and at the end of the HDI follow up by the psychiatrist responsible for the HDI with specialization on children and adolescents psychiatry. This professional also performed the diagnostic evaluation of all the patients, throughout clinical history, mental state exam, and applying the diagnostic criteria from DSM-IV.

The legal guardian/responsible for the patient were informed regarding the research and was invited to sign the informed consent term. To adolescents (older than 12 years old), the research was explained together with the responsible and the adolescent also signed a specific term. The research was approved by the Ethic Committee from the Clinical Hospital from the Medical Faculty from University of Sao Paulo. 


\subsection{Statistical analysis}

Initially, descriptive analysis of the social demographic characteristics and clinical aspects were performed with the total sample. For this study, the following data were analyzed: gender, age, psychiatric diagnosis, referral source, living situation, family dynamics, presence of psychiatric disorders among family members, and score in the CGAS and CGI.

To evaluate the clinical improvement obtained with the HDI interventions, the score of the CGAS and CGI were compared from the beginning and at the end of HDI follow up. The non parametic test of Wilcoxon was used, once the variables do not respect the normal distribution (evaluated by the Anderson-Darling test). On the analysis of the predictive factors of dropout, it was considered as dropout if the patient was absent for five days (consecutively or not) without a proper justification. It was also considered as drop out if the responsible requested for treatment discontinuation. The sample was separated into those who had completed the treatment plan and those who dropped out. An univariate analysis was performed comparing all the variables between these two groups (adhered $\mathrm{x}$ dropout). The variables that presented statistical significance were selected to compose the identification model of predictive factors of dropout. The selected variables in this model were: age, gender, referral source, presence of psychiatric disorders among family members, family conflicts and score of CGI and CGAS.

The two groups were compared using the Mann-Whitney test to continuous variables and using the chi-square test for the categorical variables. To analyze the relation of the studied variables a generalized linear binomial model were applied. A significance level of 5\% was used for all tests.

\section{Results}

\subsection{Characteristic of psychiatric infant day hospital's patients}

In this study, 62 patients were studied. There was no refusal to participation. The mean age of the studied patients was 13 years old (standard deviation: 3.1 years). Thirty five patients (56.5\%) were men. Table 1 presents the sample's sociodemographic characteristics. Sixty patients (96.8\%) were living with a parent, in 32 (51.6\%) cases there were no parental union. In half of the cases it was observed absence of one parent figure, in only $2(3.3 \%)$ the absence was for the maternal figure. Forty-seven patients $(75.8 \%)$ had at least one brother/syster.

\begin{tabular}{|l|l|l|}
\hline \multirow{3}{*}{ Gender } & Male & $35(56.5 \%)$ \\
\cline { 2 - 3 } & Female & $27(43.5 \%)$ \\
\hline \multirow{5}{*}{ Living situation } & Outpatient & $30(48.4 \%)$ \\
\cline { 2 - 3 } & Private Clinic & $17(27.4 \%)$ \\
\cline { 2 - 3 } & Inpatient unit & $10(16.1 \%)$ \\
\cline { 2 - 3 } & CAPSi & $5(8.1 \%)$ \\
\hline \multirow{2}{*}{ Parental union } & With parent & $60(96.8 \%)$ \\
\cline { 2 - 3 } & With family member & $1(3.2 \%)$ \\
\hline Absence of parent figure & Yes & $30(48.4 \%)$ \\
\cline { 2 - 3 } & No & $32(51.6 \%)$ \\
\hline Family dynamics & Both parents present & $29(46.8 \%)$ \\
\cline { 2 - 3 } & Father absence & $31(50 \%)$ \\
\cline { 2 - 3 } & Mother absence & $2(3.2 \%)$ \\
\hline & Family conflicts & $53(83.9 \%)$ \\
\hline
\end{tabular}




\begin{tabular}{|l|l|l|}
\hline \multirow{4}{*}{} & Domestic Violence & $12(19.4 \%)$ \\
\cline { 2 - 3 } & Physical abuse & $7(11.3 \%)$ \\
\cline { 2 - 3 } & Emotional abuse & $35(56.5 \%)$ \\
\cline { 2 - 3 } & Sexual Abuse & $3(4.8 \%)$ \\
\hline
\end{tabular}

Table 1: Sociodemographic characteristics from patients in follow-up at HDI (n=62).

The vast majority $(83.9 \%, \mathrm{n}=53)$ referred occurrence of family conflicts. It was identified $12(19.4 \%)$ cases of exposure to domestic violence. Thirty-five patients $(56.5 \%)$ reported occurrence of some type of maltreatment: 35 $(56.5 \%)$ had already suffered emotional abuse, 7 (11.3\%) physical abuse and $3(4.8 \%)$ sexual abuse. Among patients who had suffered maltreatment $(n=35), 20(57.1 \%)$ reported one type of abuse, $8(22.9 \%)$ were exposed to two different kinds of abuse, and 7 (20\%) were exposed to three.

Table 2 presents the clinical information from the sample. The most prevalent initial diagnostic was Mood Disorder $(\mathrm{n}=28,45.1 \%)$, followed by Emotional and Behavior Disorders that Commonly show in Childhood or Adolescence $(\mathrm{n}=18,29 \%)$. Thirty-seven patients $(59.6 \%)$ had a psychiatric comorbidity.

\begin{tabular}{|c|c|c|}
\hline \multirow[t]{10}{*}{ Initial Diagnostic* } & Mood (Affective) Disorder & $28(45.1 \%)$ \\
\hline & $\begin{array}{l}\text { Behavioral and emotional disorders with onset usually } \\
\text { occurring in childhood and adolescence }\end{array}$ & $18(29 \%)$ \\
\hline & Neurotic, stress related and somatoform disorders & $12(19 \%)$ \\
\hline & Personality disorders & $7(11.2 \%)$ \\
\hline & Disorders of psychological development & $6(9.6 \%)$ \\
\hline & Mental retardation & $6(9.6 \%)$ \\
\hline & Schizophrenia ,schizotypal and delusional disorders & $5(80.6 \%)$ \\
\hline & $\begin{array}{l}\text { Behavior syndromes associated with physiological } \\
\text { disturbances and physical factors }\end{array}$ & $4(6.4 \%)$ \\
\hline & $\begin{array}{l}\text { Mental and behavioral disorders due to psychoactive } \\
\text { substance use }\end{array}$ & $2(3.2 \%)$ \\
\hline & Organic, including symptomatic, mental disorders & $1(1.6 \%)$ \\
\hline \multirow[t]{2}{*}{ Clinical Evaluation } & CGI initial & $5( \pm 1.526)$ \\
\hline & CGAS initial & $36( \pm 6.82)$ \\
\hline \multirow{4}{*}{$\begin{array}{l}\text { Presence of family } \\
\text { members affect by a } \\
\text { psychiatric disorder }\end{array}$} & No family member affected & $18(29 \%)$ \\
\hline & Parent or siblings & $30(48.4 \%)$ \\
\hline & Grandparent & $9(14.5 \%)$ \\
\hline & Uncles or Cousin & $16(25.8 \%)$ \\
\hline \multirow{3}{*}{$\begin{array}{l}\text { Family psychiatric } \\
\text { disorders }\end{array}$} & Mood (Affective) disorders & $19(30.6 \%)$ \\
\hline & $\begin{array}{l}\text { Mental and behavioral disorders due to psychoactive } \\
\text { substance use }\end{array}$ & $13(21 \%)$ \\
\hline & Neurotic, stress related and somatoform disorders & $9(14.5 \%)$ \\
\hline
\end{tabular}

*The percentages totaled more than $100 \%$ due to presence of comorbidity.

Table 2: Clinical characteristics from patients in follow-up at HDI and their families $(n=62)$. 
Regarding family history of psychiatric disorders, $44(71 \%)$ patients had at least one relative with a psychiatric diagnosis - in 30 of the cases (68.2\%) the affected family member was a parent or a sibling. The most frequent diagnostic among family members was Affective Disorders (30.6\%), followed by Substance Use Disorder (21\%) and Anxiety Disorders (14.5\%).

\subsection{Evaluation of HDI clinical effectiveness}

The analysis of HDI effectiveness was performed with the total sample, including patients that completed the three months follow-up and those who dropped out. The mean C-GAS at the beginning of the intervention was 36, and at the end of the three months it increased to 52. The mean CGI score decreased from 5 (markedly ill) to 2 (borderline mentally ill), indicating a significant improvement in the clinical situation. Both variations were statistically significant (CGAS p=0; CGI p=0) (Graphs 1 and 2).

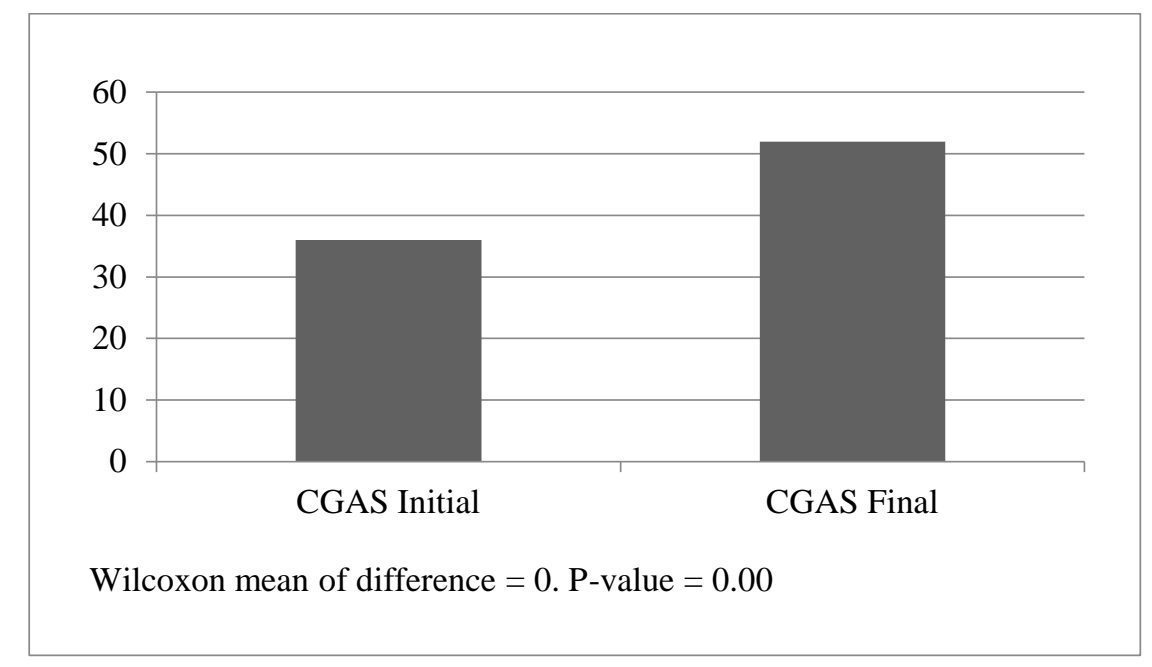

Graph 1: Global Functioning Assessment of patients at the beginning and after 3 months treatment at the Psychiatric Infant Day Hospital.

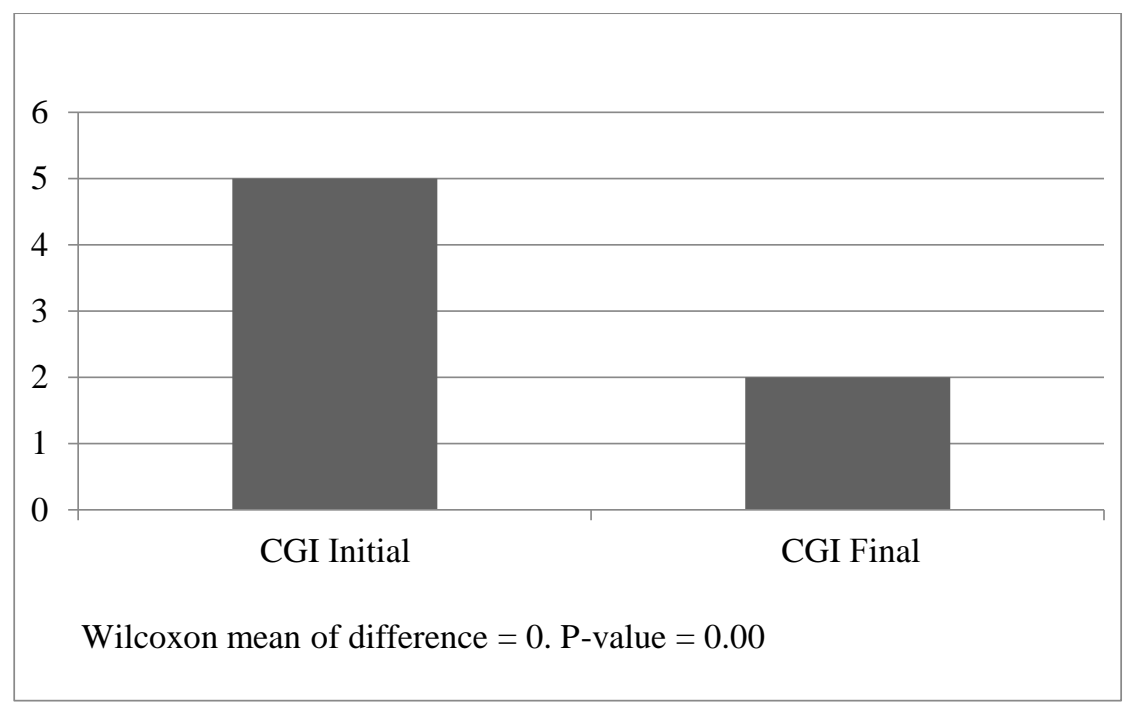

Graph 2: Global Clinical Impression of patients at the beginning and after 3 months treatment at the Psychiatric Infant Day Hospital. 


\subsection{Predictive factors of dropout in the psychiatric infant's day hospital}

From the 62 studied patients, 19 (30.6\%) dropped out of the treatment before the three months period. Table 3 presents the comparison between those who completed treatment in the HDI and those who dropped out. The variables age and presence of a family member with a psychiatric disorder were the only ones that showed statistical significance in association with dropout. Therefore, older patients have higher odds to abandon the treatment in HDI $($ Odds Ratio $=0.448 ; \mathrm{p}=0.019)$. Likewise, the presence of a relative - parent, siblings, grandparent, uncle or cousin with affective disorder increases in 2.3 times the dropout chance (Odds Ratio $=2.303 ; \mathrm{p}=0.003$ ).

\begin{tabular}{|c|c|c|c|c|}
\hline Characteristics & Specification & $\begin{array}{l}\text { Adherence } \\
(n=43)\end{array}$ & $\begin{array}{l}\text { Dropout } \\
(\mathbf{n}=19)\end{array}$ & P value \\
\hline Age & Mean(standard deviation) & $12.4( \pm 2.9)$ & $13.8( \pm 3.2)$ & 0.06 \\
\hline \multirow[t]{2}{*}{ Gender } & Male & $55.8 \%$ & $57.9 \%$ & - \\
\hline & Female & $44.2 \%$ & $42.1 \%$ & 0.87 \\
\hline \multirow[t]{4}{*}{ Referral } & Outpatient & $58.1 \%$ & $26.3 \%$ & - \\
\hline & Private clinic & $23.3 \%$ & $36.8 \%$ & - \\
\hline & Inpatient unit & $11.6 \%$ & $26.3 \%$ & 0.13 \\
\hline & CAPSi & $7 \%$ & $10.5 \%$ & - \\
\hline \multirow[t]{2}{*}{ Initial Diagnostic } & Affective Disorder & $51.2 \%$ & $63.2 \%$ & 0.37 \\
\hline & $\begin{array}{l}\text { Emotional and Behavior Disorders } \\
\text { that Commonly show in Childhood } \\
\text { or Adolescence }\end{array}$ & $34.9 \%$ & $15.8 \%$ & 0.11 \\
\hline \multirow[t]{2}{*}{ Initial CGAS } & Mean & 35.860 & 37.63 & 0.35 \\
\hline & Standard Deviation & 6.446 & 7.67 & - \\
\hline \multirow[t]{2}{*}{ Initial CGI } & Mean & 4.953 & 4.789 & 0.49 \\
\hline & Standard Deviation & 0.925 & 0.976 & - \\
\hline Parental Union & Yes & $44.2 \%$ & $57.9 \%$ & 0.32 \\
\hline Family conflicts & Yes & $86 \%$ & $68.4 \%$ & 0.48 \\
\hline Domestic violence exposure & Yes & $18.6 \%$ & $21.1 \%$ & 1.00 \\
\hline Physical Abuse & Yes & $14 \%$ & $5.3 \%$ & 0.42 \\
\hline Emotional Abuse & Yes & $51.2 \%$ & $68.4 \%$ & 0.20 \\
\hline Sexual Abuse & Yes & $4.7 \%$ & $5.3 \%$ & 1.00 \\
\hline \multirow{3}{*}{$\begin{array}{l}\text { Psychiatric diagnostic } \\
\text { among family members }\end{array}$} & Substance Use Disorder & $20.9 \%$ & $21.1 \%$ & 1.00 \\
\hline & Anxiety disorder & $20.9 \%$ & 0 & 0.04 \\
\hline & Affective disorder & $18.6 \%$ & $57.9 \%$ & 0.03 \\
\hline
\end{tabular}

Table 3: Patients characteristics of those who completed the treatment in HDI versus dropout patients.

\section{Discussion}

To the extent of the authors' knowledge, this is the first Brazilian study focused exclusively on the analyses of the effectiveness of a highly complex psychiatric service exclusive to children and adolescents. With the presented data, it was possible to verify the patient's clinical improvement and the effectiveness of the interventions performed at HDI during the three months follow-up and to identify some predictive factor of dropout: older patients and those with a family member with history of affective disorder present poorer adherence to this intervention. 
Regarding patients characteristics, most of the attended population is male $(56.5 \%)$, which is in accordance to what is seen in other psychiatric services for this age (23-25). The prevalence of males can be a consequence of the higher prevalence of externalizing disorders in this group, which is the main demand for psychiatric treatment in childhood and adolescence.

Barely all the patients live with their parent. That was expected, since social and family support is one of the admissions criteria for the HDI. However, the family dynamics were altered in most of the patients $(83.9 \%)$, with more than half referring emotional abuse. Exposure to maltreatment and interfamily aggression, physical and sexual abuse, although less frequent were also detected. Instable family dynamics are important risk factors to the development and destabilization of mental disorders [23]. The presence of these two factors in our sample may be contributing to the aggravation of the clinical picture resulting in the necessity of a more intensive treatment - the day hospital. Therefore, to offer adequate treatment to these patients, the HDI treatment plan must provide interventions for family care - family therapy, parental training.

According to the presented data, the treatment offered by the HDI was effective to increase the patients' clinical condition. Other international studies had already confirmed the effectiveness of day hospital interventions, but with variable results. The best results were shown in patients with mood and anxiety disorders [17]. On the other hand, patients with psychotic and conduct disorders showed worse responses [12]. In our study, there was no difference in the clinical improvement among different disorders.

The length of the intervention is also a factor that impacts on the clinical improvement [18,19], which was also verified by our study. The CGAS of those who dropped out before the three months follow-up (C-GAS=47.79 \pm 12.48) was lower than those that completed the treatment (C-GAS=54.93 \pm 9.18 ), even though this difference was not statically significant. Probably, the parents who did not see improvement in their children had more tendencies to interrupt the treatment [26], which shows the importance of addressing to family expectations regarding the treatment in order to increase the chance of completing treatment length so clinical improvement can occur. Other studies also demonstrate that family intervention contributes to pharmacological adherence even with adult patients [27].

The identification of the patient profile that is in higher risk of dropout is important to direct efforts to keep them in treatment, and in this way, increase the effectiveness of the intervention. Some researches point that older patients had more independency and tended to stay at treatment [28]. That is in disagree with what was shown in this study, since the older the patient, the higher the risk of dropping out. However, other research suggests that this could be due to the difficulty of facing the resistance of patients from different ages: it is more difficult to obligate an adolescent to do something against his/her will than a small child. As the follow-up in the HDI requests daily presence it can be more difficult to adolescents to withdraw of their activities and friends for three months than it is to children. Therefore, it would be more difficult to the adolescents' responsibles to keep them in treatment, against their will, resulting in dropping out. 
Furthermore, some parent and family characteristics influence in treatment adherence: the presence of internalizing disorders in parents increases the chance of early dropout of the child's treatment [26]. The same was verified in our study, in which the presence of affective disorders in family members increased the dropout risk. Possibly, families that have other members who suffer with mental problems have more difficult to manage the different demands for treatment, increasing the absences and leading to interruption of treatment [27]. Besides, the dysfunctional relationship with close relatives is related to poorer pharmacologic compliance [29].

Conversely, patients with altered familiar dynamics showed higher tendency to treatment adherence. Even though this difference was not statically significant, it can be an indicative that these families that require a more intensive care and support tend to stay at the service when these needs are attended. Likewise, patients with history of physical abuse had more tendency to complete the treatment, what can also be an indicative of parents who do not know how to treat their children properly, and once receiving help and orientation at HDI, they stayed longer.

This study has some limitations, such as the small sample and a lack of control group. However, the goals of this study were to identify the profile of the patients who benefit the most from HDI interventions and to verify its effectiveness. Even with a small sample, it was possible to identify the positive impact of the HDI interventions on clinical improvement of the patients. It would be important to perform more studies to compare the effectiveness of different interventions and also compare, among all activities performed, which has the higher therapeutic effect.

Also, it was not applied any standardized instrument to the diagnostic assessment, family dynamic evaluation and maltreatment measures. However, the same professional - with specialization in the field - performed all the assessments and as the patients stay the whole day it was possible to apply specifics interview techniques to collect information regarding family dynamics and proper diagnostic. The psychiatric interview, even though is more burdensome for research, brings more reliable data [30]. Finally, the evaluation of the HDI effectiveness was restricted to the end of the intervention. More studies should be performed to access the remaining of clinical improvement throughout time (6 to 12 months).

Despite of the limitations, the results point to the importance of family care to avoid early dropout and therefore, contribute to clinical improvement. This is the first Brazilian study that describes the profile of the population that is attended at HDI, the factors associated with dropout and establishing its effectiveness. Further research is needed to evaluate the effectiveness of this service in other contexts to better direct the resources and contribute to better public policies in this area. Even so, the HDI was effective in the stabilization of severe psychiatric disorders of children and adolescents, being an important service in the mental health care network in Sao Paulo.

\section{Conflict of Interest}

The authors have no conflict of interest or financial relationship relevant to this article to disclose. 


\section{References}

1. Roberts RE, Attkisson CC, Rosenblatt A. Prevalence of psychopathology among children and adolescents. American Journal of psychiatry 155 (1998): 715-725.

2. Fleitlich BW, Goodman R. Epidemiologia. Rev. Bras. Psiquiatria 22 (2000): 02-06.

3. Fleitlich-Bilyk B, Goodman R. Prevalence of Child and Adolescent Psychiatric Disorders in Southeast Brazil. Journal of the American Academy of Child \& Adolescent Psychiatry 43 (2004): 727-734.

4. Associação Brasileira de Psiquiatria (ABP). Pesquisa sobre sintomas de transtornos mentais e utilização dos serviços em crianças brasileiras. Brazil. Associação Brasileira de Psiquiatria (2008).

5. Avanci JQ, Assis SG Oliveira RCV, Ferreira RM, et al. Fatores associados aos problemas de saúde mental em adolescentes. Psicologia: Teoria e Pesquisa 23 (2007): 287-294.

6. Patel V, Flisher AJ, Hetrick S, et al. Mental health of young people: a global public-health challenge. The Lancet 369 (2007): 1302-1313.

7. Amstalden ALF, Hoffmann MCCL, Monteiro TPM. A Politica de Saude Mental Infanto-Juvenil: Seus Percursos e Desafios. São Paulo, Brazil. Hucitec (2010): 33-45.

8. Lauridsen-Ribeiro E, Tanaka OY. Organização dos Serviços no Sistema Único de Saude para o Cuidado de Crianças e Adolescentes com Problemas de Saude Mental. São Paulo, Brazil. Hucitec (2010): 142-169.

9. Ferreira M, Pereira M. Cuidado em saúde mental: a escuta de pacientes egressos de um Hospital Dia. Revista Brasileira de Enfermagem 65 (2012): 317-323.

10. Moraes C, Abujadi C, Ciasca SM, et al. Força-tarefa brasileira de psiquiatras da infância e adolescência (carta ao editor). Rev. Bras. Psiquiatr 30 (2008): 290-301.

11. Ministério da Saúde. Saúde Mental em Dados 12. Brazil. Ministério da Saúde Brasileiro (2015).

12. Granello DH, Granello PF, Lee F. Measuring treatment outcome in a child and adolescent partial hospitalization program. Administration and Policy in Mental Health and Mental Health Services Research 27 (2000): 409-422.

13. Miguel EC, Gentil V, Gattaz WF. Clínica psiquiátrica: a visão do departamento e do instituto de psiquiatria do HCFMUSP. First Edition, Brazil, Publisher Manole (2011).

14. Clark SE, Susan J. Effectiveness of Day Treatment for Disruptive Behaviour Disorders: What Is the LongTerm Clinical Outcome for Children? Journal of the Canadian Academy of Child and Adolescent Psychiatry 21 (2012): 204-212.

15. Kiser L, Millsap PA, Hickerson S, et al. Results of Treatment One Year Later: Child and Adolescent Partial Hospitalization. Journal of the American Academy of Child \& Adolescent Psychiatry 35 (1996): 81-90.

16. Mayes S, Krecko VF, Calhoun SL, et al. Variables related to outcome following child psychiatric hospitalization. General Hospital Psychiatry 23 (2001): 278-284.

17. Larivière N, Desrosiers J, Tousignant M, et al. Who Benefits the Most from Psychiatric Day Hospitals? A Comparison of Three Clinical Groups. Journal of Psychiatric Practice 15 (2010): 93-102.

18. Barkeland F, Lundwall L. Dropping out of treatment: a critical review. Psychological bulletin 82 (1975): 738.

19. Pekarik G. Improvement in clients who have given different reasons for dropping out of treatment. Journal of Clinical Psychology 39 (1983): 909-913. 
20. Melo, A. Guimarães, M. Factors associated with psychiatric treatment dropout in a mental health reference center, Belo Horizonte. Rev. Bras. Psiquiatr. 27 (2005): 113-118.

21. Lima MCP, Botega NJ. Hospital-dia: para quem e para quê?.Rev. Bras. Psiquiatr., São Paulo 23 (2001): 195-199.

22. Lima MCP. Hospital-dia da Faculdade de Medicina de Botucatu - Unesp: estudo descritivo da população atendida. Interface (Botucatu), Botucatu 3 (1999) : 174-175.

23. Stefanovics EA, Filho MV, Rosenheck RA, et al. Functional outcomes of maltreated children and adolescents in a community-based rehabilitation program in Brazil: Six-month improvement and baseline predictors. Child abuse and neglect 38 (2014): 1231-1237.

24. Scivoletto S, Silva TF, Cunha PJ, et al. The impact of psychiatric diagnosis on treatment adherence and duration among victimized children and adolescents in São Paulo, Brazil Clinics 6 (2012): 3-9.

25. Esposito, BP, Savoia MG. Atendimento especializado a adolescentes portadores de transtornos psiquiátricos: um estudo descritivo. Psicol. teor. Prat 8 (2006): 31-40.

26. Wergeland GJH, Fjermestad KW, Marin CE, et al. Predictors of dropout from community clinic child CBT for anxiety disorders." Journal of anxiety disorders 31 (2015): 1-10.

27. Hartung D, Low A, Jindai K, et al. Interventions to Improve Pharmacological Adherence Among Adults With Psychotic Spectrum Disorders and Bipolar Disorder: A Systematic Review. Psychosomatics 58 (2017): 101-112.

28. Baruch G, Gerber A, Fearon P. Adolescents who drop out of psychotherapy at a community-based psychotherapy centre: A preliminary investigation of the characteristics of early drop-outs, late drop-outs and those who continue treatment. British Journal of Medical Psychology 71 (1998): 233-245.

29. Stewart SL, Baiden P. An exploratory study of the factors associated with medication nonadherence among youth in adult mental health facilities in Ontario, Canada. Psychiatry Res. 207 (2013): 212-217.

30. Kessler RC, Avenevoli S, Green J, et al. National Comorbidity Survey Replication Adolescent Supplement (NCS-A): III. Concordance of DSM-IV/CIDI diagnoses with clinical reassessments. Journal of the American Academy of Child and Adolescent Psychiatry 48 (2009): 386-399.

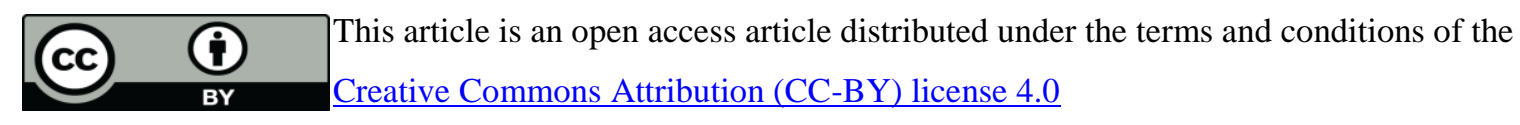

